\title{
AC 2009-491: DEFINING THE IMMEDIATE LEARNING OUTCOMES OF AN UNDERGRADUATE INTERNSHIP PROGRAM
}

Bryan Dansberry, University of Cincinnati 


\title{
Capturing immediate learning outcomes of undergraduate internships: NASA's Undergraduate Student Research Project
}

\begin{abstract}
Government internship and co-op programs fluctuate greatly in size and scope from year-to-year. A major source of this instability comes from volatility in the administrative priorities set at the highest levels of these agencies. In the face of rapidly shifting administrative priorities, it is essential that experiential program managers capture data defining the full value of outcomes produced by their programs to the benefit of their organizations.

In 2008, the Undergraduate Student Research Project, NASA's largest agency-wide internship program, revised its student and mentor evaluations, gathering new data on outcomes whose value had not previously been captured. This paper presents a preliminary discussion of the data collected through these new survey instruments. It includes data connecting the learning produced to many of the ABET a-k demonstrated abilities criteria as well as data on the changes in professional self-image, confidence, and commitment to career path. In addition, implications of the metrics which can be calculated from the raw data are discussed in regards to the value placed on that learning by the student participants.
\end{abstract}

\section{Introduction}

When viewed from the broadest employer perspective, full-immersion experiential programs such as internships or co-op generate positive outcomes in three general areas:

1. student competencies (learning)

2. useful productivity (task completion)

3. retention into the workforce (graduation, advanced degrees, employment)

Traditionally, metrics collected for NASA internships focused solely on retention outcomes. Retention data requires longitudinal tracking of student alumni to determine graduation rates, career choices, and employment history. While important, capturing this information requires a high level of effort often beyond that available to experiential program managers in government organizations. Additionally, retention outcomes require years to emerge as students complete their undergraduate degrees, decide whether or not to pursue graduate programs, and finally enter the workforce. Because of this long time-lag between participation in the experiential program and eventual hiring into the workforce, retention data can be a poor tool for government program managers looking to implement continuous improvements to their programs in the short term. Moreover, retention data alone often does not carry the weight necessary to defend experiential programs from budget cuts in times of fiscal "belt-tightening." When budgets are tight, financial decisions are made more on the basis of immediate impact as opposed to longterm benefits.

Outcomes in the areas of student learning and productivity hold the promise of providing more immediate information to program managers in monitoring the rigor and challenge of student experiences, maximizing the quality of the selection process in matching specific students to 
specific mentors and projects, and in capturing student growth in areas directly related to the ABET a-k criteria. Additionally, data gathered in the area of productivity can be used to estimate the value of the work produced by students to the organization - a metric which can carry significant weight in defending experiential program budgets during difficult economic times.

In 2008, manager's of NASA's Undergraduate Student Research Program (USRP) instituted new end-of-internship surveys for both students and mentors designed to better capture outcomes generated in the areas of student learning and productivity. Data generated from these instruments included:

1. Two new program "return-on-investment" (ROI) metrics designed to estimate the overall value of student learning and student productivity generated by USRP internships;

2. Defining areas of learning generated allowing connection to some of the ABET a-k criteria; and

3. Defining areas of affective learning fostered by the experience.

Focusing primarily on learning outcomes, the following sections define the ROI measures and present a preliminary discussion of the data collected for USRP internships during the 2008 calendar year.

\section{NASA's Undergraduate Student Research Project}

With an annual budget of $\$ 4.0$ million, USRP is NASA's largest agency-wide internship program for science and engineering students. In order to be eligible, students must be enrolled full-time in an accredited engineering, physical science, biological science, computer science, or mathematics degree program. USRP is open to undergraduate students, sophomore and above, who have a minimum 3.0 cumulative GPA on a 4 point scale. USRP participants must also be US Citizens. In 2008, 3,000 qualified students completed applications for USRP internships, representing over 900 academic institutions. The 319 students selected represented 202 institutions, 43 states, and Puerto Rico.

USRP internships are full-time (40 hrs/wk), stipend-paid, discipline-specific experiences. Student candidates are selected by individual NASA technical mentors based on the required skills and aptitudes necessary for their specific research project or engineering task-load. In order to assure the experience offered matches their interests and career goals, students are provided a short description of the specific work-assignment in their official internship offer. Students also have the opportunity to seek clarification before accepting the internship. Figure 1 shows the high level of satisfaction in this matching process by USRP mentors during the summer and fall 2008 sessions. A total of $97 \%$ of the mentors rated the matching of their intern to their project to be above average or excellent based on their previous experiences with student interns and co-ops.

In addition to the experience gained through the work assignments provided by their mentors, USRP students are required to write and submit a 10 page technical paper on their core research or engineering activities by the end of their internship. These reports are required to follow AIAA conference paper guidelines and are collected by USRP project managers. Additionally, 
all interns are required to either give an exit technical presentation to upper management within the technical organizations they have been embedded within, or to participate in a poster session attended by personnel across the particular NASA center at which they worked. These requirements provide extensive technical communication experience intended to benefit the students while simultaneously fostering organizational communications within NASA.

Figure 1. Quality of Student-Mentor Matching

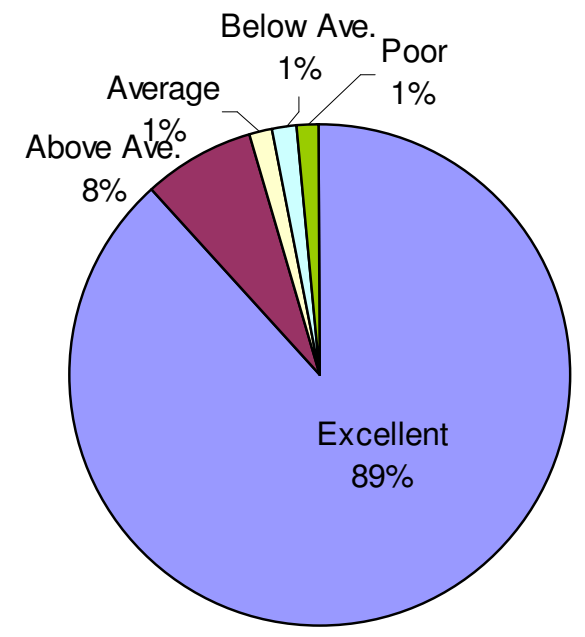

In 2008, there were 319 USRP internships hosted by 12 NASA work-sites over 3 internship sessions: spring (74), summer (149), and fall (96). Summer USRP internships are 10 weeks in length, while spring and fall internships are 15 weeks long. The distribution of internships by worksite and session can found in Table 1.

\section{Table 1. Distribution of USRP Internships}

\begin{tabular}{|r|c|}
\hline Location & No. \\
\hline Ames & 34 \\
\hline Dryden & 4 \\
\hline Glenn & 46 \\
\hline Goddard & $\mathbf{1 6}$ \\
\hline JPL & 48 \\
\hline JSC & 37 \\
\hline KSC & 33 \\
\hline Langley & 26 \\
\hline Marshall & 44 \\
\hline Stennis & 12 \\
\hline Wallops & 13 \\
\hline White Sands & 6 \\
\hline Total & 319 \\
\hline
\end{tabular}

\section{Retention Outcomes}

NASA's Office of Education annually collects data defining the retention outcomes of its higher education projects. Data collected is limited to the fiscal year in which funding was provided. Of the 319 USRP interns in 2008 , only 18 of these students had graduated at the time this data was collected - thus making themselves eligible to contribute to the retention metrics. The results of those 18 graduates show that $94 \%$ have been retained in the STEM pipeline either through graduate school or employment. However, the small sample size illustrates the limited picture provided by retention data alone. For USRP, the retention outcomes reported are based on only $5.6 \%$ of the 
participants. Whether this data is favorable or unfavorable, the results are not necessarily indicative of the overall USRP student population.

\section{Student Productivity}

Beginning in the summer session of 2008, USRP project managers implemented a new mentor end-of-internship survey instrument which includes the following question:

"In an attempt to quantify the overall value of the work produced by this intern to your organization, please estimate the relative percentage you would assign this students' overall productivity relative to a typical fresh-out (recent graduate) new hire in your organization."

A total of 96 mentors responded to this survey question, representing $39 \%$ of the total summer and fall USRP internship experiences. Based on mentor responses the overall average productivity ratio was almost precisely 1.0. This ratio can be used to estimate the dollar value of student intern productivity to NASA. By taking the average starting salary and benefits of NASA B.S. level new-hires in 2008 (as provided by NASA), one can generate an estimated value of the productivity generated by the USRP interns in 2008. The equation for generating this metric is:

Productivity $(\$ \$)=$ mentor rating $x$ ave. starting salary+benefits $x$ total length of USRP internships

In 2008, student productivity was calculated to be $\$ 6$ million. This represents a positive return on investment since the total cost to NASA for USRP is \$4 million/year. While still under preliminary evaluation, this student productivity metric holds great promise in capturing an output of experiential programs not previously considered in the cost-benefit analysis typically used to justify educational projects in government agencies.

\section{Student Learning}

Of greatest interest to ASEE members may be the learning outcomes of experiential programs such as USRP. Beginning in the spring session of 2008, USRP project managers implemented a new student end-of-internship survey instrument designed to collect additional information on specific cognitive and affective areas of learning. Table 2 shows the percentage of USRP interns who indicated their experience provided them growth opportunities in areas closely aligned to ABET a-k criteria. This data is based on 212 student responses representing $67 \%$ of the 2008 USRP internships. Overall, this data indicates that USRP internship experiences are appropriately rigorous and challenging, providing student's ample opportunity to grow in many of the areas considered critical in producing a highly qualified pool of future engineers and scientists for the nation's technical workforce.

Table 2. Percentage of USRP interns indicating significant growth.

$\begin{array}{ll}\text { Professional/Technical Communication } & 94 \% \\ \text { Conceptual/Analytical Ability } & 99 \% \\ \text { Learning/Applying Knowledge } & 97 \% \\ \text { Professional Qualities } & 94 \% \\ \text { Teamwork } & 82 \% \\ \text { Leadership } & 76 \% \\ \text { Technology } & 95 \%\end{array}$


Work Culture $\quad 97 \%$

Organization/Planning $\quad 95 \%$

In addition, USRP interns were asked a series of questions designed to determine how their USRP experience affected their commitment and attitude in regards to their current career path. Table 3 shows the responses of the students to these questions. The number given represents the average response on a $5 \mathrm{pt}$ Lickert scale where 5 indicates strong agreement with the statement. Considering the fact that over 50\% of the 2008 USRP interns were seniors, the results shown are another indication of the strong impact experiential programs have on student development.

Table 3. Student responses to affective questions in USRP survey.

This experience...

...helped me determine my own strengths and weaknesses

...increased my professional self-confidence

...increased my academic motivation

4.31

...increased my understanding of my chosen profession

4.08

...helped me to clarify my career plans and options

4.17

...helped prepare me to achieve my career goals

Finally, in an attempt to create a value metric similar to that for student productivity, USRP project managers asked the following question on student surveys:

"Please relate the total value (educational learning, professional growth, etc...) of your internship experience to the value you get from a typical semester (or quarter) at your institution. Please quantify your answer in terms of credit hours."

The average response to this question was 12.5 credit hours. Applying this value to all 319 internships results in an estimated quantity of learning generated by USRP internships roughly equivalent to 4,000 credit hours. Converting this figure to a dollar amount is somewhat more complex than the conversion for productivity. Depending on whether you apply a strict cost per credit hour national average, or look at the total average cost for a semester of school, the dollar value equivalent can range from $\$ 2$ million to $\$ 4$ million. In addition, when looking at the individual student responses, there are clearly two groupings. One group, representing roughly a third of the respondents, tended to rate the experience between 3-9 credit hours This group indicated in their comments that the technical knowledge gained was equal to one or more lab courses. The second group, representing most of the remaining $66 \%$ tended to rate the experience from 15 to 25 credit hours. Their comments indicated that they were including experiential, inter-personal, and professional development and networking aspects of the internship. Many of these students indicated that the true rating should probably be even higher than they indicated, but that the question was difficult as it was asking them to compare "apples to oranges."

Overall, further analysis will be necessary to determine whether this metric can provide useful, meaningful data to experiential program managers.

\section{Summary Remarks}


In 2008, the Undergraduate Student Research Project, NASA's largest agency-wide internship program consisting of 319 internships at 12 NASA work-sites, revised its student and mentor evaluations, gathering new data on outcomes whose value had not previously been captured. While this data is only now beginning to be evaluated, initial results were presented along with possible implications.

Data presented included metrics defining the overall value of student productivity to the technical mentors and to the overall NASA technical mission. This metric indicates that the value of the work produced by USRP interns in 2008 exceeds the cost of the program by $50 \%$. While further analysis is necessary to look for trends between semester and summer internships as well as across individual work-sites, this metric hold great promise as a tool for better capturing the full benefit of internship programs to the funding agency.

Data defining the areas of learning as defined by the student interns was also presented. This data indicates that USRP students are being challenged and undergoing significant growth in many of the areas deemed critical by ABET in preparing students for technical careers. Additionally, data was collected to identify student's perceived changes in their level of professional confidence, commitment to their academic program, and clarity and enthusiasm for their career plan. 